\title{
Registered nurses as role models for healthy lifestyles
}

\author{
AUTHORS \\ PENNY HEIDKE BN GDLT M HSC PHD (cand) ${ }^{1}$ \\ WENDY L MADSEN BA MHSC PhD GCFL ${ }^{2}$ \\ School of Nursing and Midwifery, CQUniversity Australia. \\ ERIKA M LANGHAM MPopStud ${ }^{2}$ \\ 2 School of Health, Medical and Applied Sciences, \\ CQUniversity Australia.

\section{CORRESPONDING AUTHOR} \\ PENNY HEIDKE School of Nursing and Midwifery, CQUniversity Australia, Building A, 90 Goodchap Street, \\ Noosaville, QLD. 4566. Phone: +61 754407019 \\ Email: p.heidke@cqu.edu.au
}

\section{ABSTRACT \\ Objective: The aim of this paper is to report on registered nurses' adherence to current Australian health behaviour recommendations. Barriers and facilitators to healthy lifestyles, and their attitudes towards being role models and promoting healthy lifestyles to their patients.}

Background: It is widely accepted that a healthy diet, limiting alcohol consumption, abstinence from smoking and regular physical exercise are important components of healthy lifestyles and play a significant role in preventing chronic diseases. Nurses are well situated to contribute to providing health and patient education regarding modifiable health risk factors, however their own adherence to health behaviours may impact this.

Study design and methods: The research is a mixed methods study of 123 registered nurses from both public and private organisations in regional Queensland. Data for this paper were generated from an online survey which is the first of two phases in the broader study.

Results: Four health risk factors were examined; diet, smoking, physical exercise and alcohol consumption. BMI was also calculated and considered as a fifth risk factor. Of this sample, $13 \%$ of participants met the guidelines for fruit and vegetable intake, 5.2\% smoked, and only $24.2 \%$ exercised enough to be classed sufficiently active for their health. Of the
93.62\% of participants whom consumed alcohol, $69.3 \%$ consumed more than two standard drinks/day. The most common barriers to adhering to healthy lifestyles were shift work, long working hours and family commitments.

Conclusion: Many nurses are not adhering to healthy lifestyle recommendations. It is recommended that the health and wellbeing of our health professionals, especially nurses be considered. Providing support and resources to enable them to care for themselves, may in turn allow them to better care for patients.

Implications for research, policy, and practice: Research is needed into strategies to enable registered nurses' better work/life balance. To make a real difference to health outcomes, nurses own health and health education needs to be made a priority that is supported and implemented at multiple points: by policymakers, within nursing practice, nursing curriculum, and in healthcare institutions. Nurses need to be supported to provide health education to their patients with better resources, education, and time allocation. Future research should include studies conducted in different regions or ideally a large nationally representative sample.

Key words: lifestyle risk factors, health behaviour, physical exercise, patient education 
What is already known about this topic?

- Healthy diet, limiting alcohol consumption, not smoking and regular physical exercise are important for healthy lifestyles.

- Nurses are seen as role models for patients and the community.
What this paper adds:

- Insight into nurse's adherence to health guidelines.

- Nurses beliefs of how their own behaviours impact their role model status and the health education they provide to people they care for.

\section{OBJECTIVE}

It is widely accepted that a healthy diet, limiting alcohol consumption, abstinence from smoking and regular physical exercise are important components of healthy lifestyles and play a significant role in preventing chronic diseases. ${ }^{1}$ There is a lack of adherence to healthy lifestyles, at a population level, that has contributed to the increasing prevalence of obesity and smoking related illnesses. ${ }^{2}$ This phenomenon has attracted significant attention at both national and global levels. Nurses are well positioned to contribute to providing health and patient education regarding modifiable health risk factors. ${ }^{3}$ However, some studies report that nurse's personal adherence to healthy lifestyle recommendations is decreasing..$^{-6}$ Furthermore, nurses' own behaviours and values are believed to impact on the quality and amount of health education they provide to their patients.3,7

This paper presents the findings of an exploratory research project that considered the role of registered nurses (RNs) in promoting healthy lifestyles. Underpinning the research is the premise that whilst health education is a recognised standard for practice for Australian RNs, ${ }^{8}$ the reality of nursing practice is significantly restricting the ability of nurses to adequately meet this competency expectation. ${ }^{9}$ Furthermore, nurses' own health behaviours may be an inhibiting factor in nurses effectively promoting healthy lifestyles to others.

\section{BACKGROUND}

In Australia, the Standards for Practice require that the role of the $\mathrm{RN}$ includes the promotion and maintenance of health and prevention of illness for individuals. ${ }^{8}$ Standard 2.4 states RNs are to 'provide support and direct people to resources to optimise health-related decisions' whilst standard 3 mandates that RNs must ensure their own health and wellbeing as well as "provide information and education to enable people to make decisions and take action in relation to their health'. ${ }^{8}$ However, sometimes there is a dissonance between what nurses educate their patients on in regard to healthy lifestyles, and their own health behaviour. ${ }^{10,11}$

When RNs personally engage in behaviours that are detrimental to their own health, they not only put the profession in a negative light, ${ }^{12}$ but their health behaviour may negatively impact on the behaviour of others through behaviour modelling. ${ }^{13}$ Research is being undertaken to identify the cause of dissonance between what nurses say and what they do, and the rationale behind what prevents some nurses from adhering to the health behaviour they are expected to teach and model. ${ }^{5}$ In Australia, with increased attention on preventing and decreasing lifestyle-related diseases, nurses are anticipated to be behavioural role models for their patients, families and the wider community. ${ }^{14}$ When nurses adhere to healthy lifestyles it not only enhances their own health but also increases their credibility as health educators and role models. The focus of the work to date has been on the four modifiable health behaviours most commonly reported by the World Health Organization (WHO): smoking, unbalanced diet, excessive alcohol consumption and lack of physical activity. ${ }^{1}$ Little is currently known of the personal dietary and exercise patterns of the RN workforce from an Australian perspective. One crosssectional Australian study by Perry and colleagues found that even though nurses perceive they have good health, almost half indicated they had chronic disease and other health risk behaviours. ${ }^{12}$ Other worldwide studies have tended to concentrate on health behaviours in nursing students, ${ }^{13}$ obesity in healthcare workers, ${ }^{15,16}$ and the impact of shift patterns on the health of nurses, ${ }^{17,12}$ and health and chronic diseases. ${ }^{5}$ However, research into actual excess weight and associated health behaviours in nurses is limited. ${ }^{18}$ Of the studies conducted on nurses, most have identified prevalence rates of health risk factors amongst nurses at least equivalent to, or greater than general population levels.5,12

The relationship between nurse's personal health behaviours and nurse's counselling of patients about health issues has been examined in several studies. Researchers have found that nurses who practised positive healthy behaviours were more likely to advise patients in relation to these and reported that compliance of health promoting behaviours in patients had been influenced by the behaviours of those nurses caring for them. ${ }^{7}$

The Australian guidelines for adults' state: ‘Guideline 1 drinking no more than two standard drinks on any day reduces the lifetime risk of harm from alcohol-related disease or injury'. ${ }^{19}$ The guidelines also recommend that to reduce the risk of injury on a single occasion ofdrinking, adults should drink 'no more than four standard drinks on a single occasion' (Guideline 2). ${ }^{19}$ Australian dietary guidelines 
recommend a daily intake of five servings of vegetables and two servings of fruit. ${ }^{20}$ The recommended national guidelines for physical activity are exercise at least five days per week, with 150 minutes or more being classed as sufficiently active and less than 150 minutes per week or less than five sessions a week classified as 'insufficiently active' to maintain health. ${ }^{21}$

There have been no studies identified that focus on RNs in regional Australia, where the general population are found to have higher rates of smoking and alcohol consumption, and lower rates of meeting physical activity and fruit and vegetable consumption than urban populations. ${ }^{22}$ This paper focuses on the first phase of a larger exploratory, sequential mixed methods study. This research aimed to measure the prevalence of modifiable risk factors in RNs within a regional Queensland area and to explore the perceptions of nurses towards promoting healthy lifestyles to their patients.

\section{METHOD}

A cross-sectional, online (SurveyMonkey ${ }^{\circledR}$ ) anonymous survey of RNs in the region was conducted $(n=123)$.

\section{DATA COLLECTION}

The survey instrument was developed using core items from the National Health Survey (NHS) and National Nutrition and Physical Activity Survey (NNPAS).21,24 Full details of the survey design and measurements are available on the ABS website. ${ }^{21}$ The instruments were adapted for this study by selecting scales or questions of direct relevance to the research aim. Questions were included that related to the health risk factors of tobacco smoking, dietary behaviours (fruit and vegetable intake), physical activity, alcohol consumption, height, weight as well as self-rated health and weight status. Self-rated health is a commonly used health outcome measure and has been found to be valid and reliable in a wide range of populations. ${ }^{25}$ The survey also included open-ended questions relating to: barriers RNs face in adopting and maintaining healthy behaviours themselves; and suggested strategies to overcome these barriers, and whether they believed that nurses who engage in unhealthy behaviours are less likely to counsel their patients on these behaviours. As the tool utilised a variety of formats in the question designs, Cronbachs alpha was unable to be used for validity. ${ }^{26} \mathrm{~A}$ copy of the final survey is available from the corresponding author on request.

\section{PARTICIPANTS}

Convenience sampling was utilised and data collected via an online survey, hosted on SurveyMonkey ${ }^{\circledR}$. The explanatory letter on the first page of the survey outlined the research project and reminded participants of the inclusion criteria, that is, RNs who lived in the study region. The survey was posted to social media accounts; that being the researchers' personal Facebook page and the local nurses Facebook group via hyperlink, asking RNs to share on their own pages and also a URL to share via email with those that did not have access to Facebook. To reduce the effects of selection bias within the limits of the study, the survey was anonymous, and nurses were asked to share as broadly as possible with colleagues.

\section{DATA ANALYSIS}

The data was downloaded from SurveyMonkey ${ }^{\circledR}$ into Microsoft Excel for checking and cleaning before being uploaded to SPSS v22 for statistical analyses. ${ }^{27}$ Frequencies and descriptive statistics were generated and checked for each variable and any statistical outliers were identified. The open-ended question data from the individual responses were analysed using both content and thematic analyses identifying key words, frequencies and themes. Content analysis was used to code the responses to the first three open-ended questions as the responses were only short. ${ }^{28}$ An inductive categorisation method was utilised in which recurring factors found in the responses were identified. ${ }^{29}$ The final open-ended question was analysed using thematic analysis as participants had responded in short paragraphs allowing emergent themes to evolve from the data.

\section{ETHICS}

The project received approval by the Human Ethics Research Review Panel at CQUniversity (PROJECT H14/07-167). Participant consent to take part in the study was indicated upon their completion and submission of the survey.

\section{RESULTS}

In total 123 responses were received of which $101 \mathrm{had}$ complete data and were subsequently analysed. The estimated population of RNs in the region is 6oo, according to Human Resource records from Qld Health and the private healthcare facilities. Therefore, the response rate was estimated to be approximately $20.5 \%$ of RN population.

The age distribution (23-65years, average 47 years) of the sample is relatively consistent with the RN population of Australia, which is 44.4 years. ${ }^{30}$ The distribution of gender in this sample was 90\% females and 10\% males. All participants were qualified RNs working: part-time (51\%); full-time (46\%); or currently unemployed (3\%). The average years of experience were 17.16 years (SD 12.435).

\section{SELF-RATED HEALTH AND WEIGHT}

Participants rated their health on a standard five-point scale from excellent to poor with the majority rating their health as being good (42\%). Participants self-rated their weight status although when their Body Mass Index (BMI) was calculated using their self-reported height and weight, estimations of weight classification were consistently inaccurate 
(see Table 1). When asked had their weight altered in the last twelve months, $22.7 \%$ reported an increase while $25.7 \%$ reported a decrease; $51.5 \%$ reported their weight had stayed the same.

\section{TABLE 1: COMPARISON OF PARTICIPANTS'} SELF-RATED WEIGHT VS. CALCULATED BMI

\begin{tabular}{|l|r|r|r|}
\hline Weight status & $\begin{array}{r}\text { Self-Rated } \\
\mathbf{( \% )}\end{array}$ & $\begin{array}{r}\text { BMI* } \\
\text { (calculated) }\end{array}$ & $\begin{array}{r}\text { Australian } \\
\text { general } \\
\text { population } \\
\text { (\%) }\end{array}$ \\
\hline $\begin{array}{l}\text { Overweight* for BMI } \\
\text { includes Overweight } \\
\text { and Obese }\end{array}$ & $57.84 \%$ & $70.21 \%$ & 63.4 \\
\hline Healthy Weight & $39.22 \%$ & $29.79 \%$ & 35.0 \\
\hline Underweight & $0.98 \%$ & $\begin{array}{r}\text { Not } \\
\text { calculated }\end{array}$ & 1.6 \\
\hline Currently pregnant & $1.96 \%$ & $\begin{array}{r}\text { Not } \\
\text { calculated }\end{array}$ & $\mathrm{n} / \mathrm{a}$ \\
\hline
\end{tabular}

Total $\mathrm{N}=102$

\section{HEALTH BEHAVIOURS}

Only 5.2\% of participants identified that they currently smoke (4.2\% daily smokers; $1 \%$ less than daily). Of those participants who responded that they did not currently smoke, $55.6 \%$ identified as ex-smokers and $15.7 \%$ as having never smoked.

Nearly all participants in this study (93.62\%) reported having consumed alcohol in the last 12 months: less than weekly (56.82\%); 1-2 days a week (17.05\%); 3-4 days a week (12.5\%); 5-6 days a week (7.95\%); and every day (4.55\%). On the occasions that they did drink alcohol in the last twelve months, $69.3 \%$ reported drinking more than the recommended two standard drinks on a single occasion, ${ }^{19}$ and $39.7 \%$ reported drinking more than the recommended four standard drinks on a single occasion. The $55-64$ year age group $(\mathrm{N}=16)$ most closely met the Australian guidelines for alcohol with $56.3 \%$ drinking within acceptable limits. ${ }^{19}$ Over the last twelve months, $8.89 \%$ said their alcohol intake had increased, $21.11 \%$ said it had decreased and 70\% said it had stayed about the same.

TABLE 2: PERCENTAGE OF PARTICIPANTS THAT MET ALCOHOL GUIDELINES

\begin{tabular}{|l|r|r|r|}
\hline \multirow{2}{*}{ Age Groups } & \multicolumn{3}{|r|}{$\begin{array}{r}\text { \% of sample that met NHRC guidelines for } \\
\text { alcohol consumption }\end{array}$} \\
\cline { 2 - 4 } & Guideline 1 & $\begin{array}{r}\text { Buth } \\
\text { Guideline 2 }\end{array}$ & $\begin{array}{r}\text { Both } \\
\text { Guidelines }\end{array}$ \\
\hline $18-24$ & 60.0 & 60.0 & 20.0 \\
\hline $25-34$ & 50.0 & 56.3 & 43.8 \\
\hline $35-44$ & 36.7 & 50.0 & 30.0 \\
\hline $45-54$ & 40.6 & 65.6 & 37.5 \\
\hline $55-64$ & 56.3 & 87.5 & 56.3 \\
\hline $65-74$ & 100.0 & 100.0 & 100.0 \\
\hline
\end{tabular}

Only $18 \%$ of participants were meeting the Australian dietary guidelines' recommended intake of vegetables (five servings per day), but $61.7 \%$ were meeting the recommended daily intake of fruit (two servings per day). ${ }^{20}$ When compared to the guidelines, $13 \%$ of participants met both the recommended daily guidelines for vegetables and fruit. The age group most likely to meet the dietary guidelines were between 45 and 54 years (30.8\%). Those who worked parttime $(15.7 \%)$ were also more likely to adhere to the dietary guidelines.

Physical activity was analysed based on whether participants met the recommended national guidelines. ${ }^{21}$ Nearly all participants $(\mathrm{N}=99)$ responded to the questions regarding their physical activity. Table 3 shows that over half of the participants exercised less than 150 minutes per week and were classified as 'insufficiently active' to maintain their health. The age group that met the guidelines the most was 45-54 years (52.9\%).

TABLE 3: COMPARISON OF PARTICIPANTS' PHYSICAL ACTIVITY TO THE RECOMMENDED GUIDELINES VS. THE AUSTRALIAN POPULATION

\begin{tabular}{|l|r|r|}
\hline $\begin{array}{l}\text { Recommended } \\
\text { Guidelines }\end{array}$ & $\begin{array}{r}\% \text { of } \\
\text { Participants }\end{array}$ & $\begin{array}{r}\% \text { of Australian } \\
\text { general } \\
\text { population }\end{array}$ \\
\hline $\begin{array}{l}\text { Sufficiently active: } \\
150 \text { mins or more and five } \\
\text { sessions per week }\end{array}$ & 24.2 & 55.5 \\
\hline $\begin{array}{l}\text { Insufficiently active: } \\
1-149 \text { mins or less than five } \\
\text { sessions/week }\end{array}$ & 59.6 & 29.7 \\
\hline $\begin{array}{l}\text { Inactive: } \\
0 \text { mins }\end{array}$ & 16.2 & 14.8 \\
\hline
\end{tabular}

\section{ADDING UP THE LIFESTYLE RISK FACTORS}

The prevalence of risk factors is frequently considered in isolation. However, there is increasing evidence that they also have an interactive and cumulative effect. ${ }^{22,31}$ Figure 1 shows the six risk factors used in the analysis for this section.

\begin{tabular}{|l|l|}
\hline RISK FACTOR & GUIDELINE IDENTIFIER \\
\hline Smoking & Current daily smoking \\
\hline Physical inactivity & Insufficient time and sessions \\
\hline Low fruit consumption & Less than two serves \\
\hline $\begin{array}{l}\text { Low vegetable } \\
\text { consumption }\end{array}$ & Less than five serves \\
\hline $\begin{array}{l}\text { Risky alcohol } \\
\text { consumption }\end{array}$ & $\begin{array}{l}\text { Over two standard drinks in } \\
\text { any one day }\end{array}$ \\
\hline Obesity & BMI of 30 or more \\
\hline
\end{tabular}

FIGURE 1: RISK FACTORS USED IN THE ANALYSIS FOR THIS SECTION 
TABLE 4: PERCENTAGE OF MULTIPLE RISK FACTORS COMPARED TO AGE GROUPS

\begin{tabular}{|l|r|r|r|r|r|r|r|}
\hline \multirow{2}{*}{$\begin{array}{l}\text { Age } \\
\text { Groups }\end{array}$} & \multicolumn{6}{|c|}{ \% of age group with multiple risk factors } \\
\cline { 2 - 7 } & $\mathbf{0}$ & $\mathbf{1}$ & $\mathbf{2}$ & $\mathbf{3}$ & $\mathbf{4}$ & $\mathbf{5}$ & $\mathbf{6}$ \\
\hline $18-24$ & 0.0 & 0.0 & 20.0 & 60.0 & 20.0 & 0.0 & 0.0 \\
\hline $\mathbf{2 5 - 3 4}$ & 0.0 & 6.3 & 37.5 & 25.0 & 25.0 & 0.0 & 6.3 \\
\hline $35-44$ & 3.3 & 3.3 & 6.7 & 40.0 & 40.0 & 6.7 & 0.0 \\
\hline $\mathbf{4 5 - 5 4}$ & 3.1 & 3.1 & 12.5 & 50.0 & 18.8 & 9.4 & 3.1 \\
\hline $55-64$ & 0.0 & 12.5 & 31.3 & 31.3 & 18.8 & 6.3 & 0.0 \\
\hline $65-74$ & 0.0 & 0.0 & 0.0 & 0.0 & 100.0 & 0.0 & 0.0 \\
\hline
\end{tabular}

Most participants ( $98 \%$ ) had at least one of the six risk factors listed above (Figure 1), with the majority having two to four (85\%) (Table 4). There was no significant difference in the distribution of risk factors according to gender or age. This may be attributed to the sample being mostly female and the median age 47 years.

\section{BARRIERS AND STRATEGIES}

These questions asked participants to elucidate on the barriers and strategies to adopting and maintaining healthy behaviours themselves. Participants identified two main issues regarding perceived barriers RNs face in adopting and maintaining healthy behaviours themselves. Shift work and working long hours were cited by many participants (61.5\%), with time and family commitments also being cited by almost half (47.4\%). The detrimental impact of shift work was described by one participant:

'Shift work and being on our feet all day, early starts, makes me tired, so I am more reluctant to go to the gym or go for a run. Doing shift work makes it hard to get into a good routine with diet sometimes also.'

Whilst the lack of time was explained by another participant:

'Time poor. I go to work, long hours, then come home to family, kids, chores and it is often extremely difficult to find ten minutes to do a survey let alone find 30 minutes to walk around the block.'

When considering strategies to overcome perceived barriers to adopting and maintaining healthy lifestyles, prioritising, planning and making time was reported as a potential strategy by $34.4 \%$ of participants, whilst $28 \%$ suggested better rostering and improved work-life balance as well as education and support. One participant outlines how planning could be a strategy:

'Taking the time to plan healthy meals ahead of time and ensure that healthy snacks are brought to work all the time so that the temptation of vending machine food is not there.'
Whilst another discussed an improvement to rostering:

'If shift rotation must be done, do the shifts in blocks so that a routine for eating, sleeping and living can be established.'

Over half of the participants believed that RNs who engage in unhealthy behaviour were less likely to counsel their patients on these behaviours. This is at odds with the belief held by the majority of participants that an RN has an important role in the provision of health education. While there was no statistically significant relationship, there was a slight tendency towards not providing health education by those not engaging in the healthy behaviours and that they saw this in terms of hypocrisy, credibility and self-efficacy.

The feeling of hypocrisy was highlighted by one participant:

'It's easy to give education on healthy behaviours, however, up until I quit smoking six months ago I always felt like a hypocrite when advising others to quit smoking. I think people who are engaging in healthy behaviours would be more likely to provide education as people who don't would probably feel ashamed or feel like a hypocrite.'

Another participant emphasised the importance of credibility:

'If you aren't walking the walk you can't talk the talk. Nurses who are overweight, smoke, eat loads of takeaway do not portray healthy habits to patients and patients would be less likely to want to change if they see that in nurses who do the same as themselves.'

Those who believed nurses' own health behaviours did not influence their health education practices saw health education as part of their job that was not reflective of their own lifestyle. One participant stated it is not taken into consideration:

'Because when it comes to looking after patients and providing education this is not really taken into consideration what we do in our own lives. It's like the saying do as I say, not as I do.'

The participants reported that their knowledge and experiences made them more relatable and authentic and that they believed patients felt they could understand the challenges and barriers to achieving good health.

\section{LIMITATIONS}

The current study has a number of limitations that are worth highlighting. The study utilised a convenience sample conducted in a single regional area, which means the results are not generalisable to RNs nationally. The geographic restriction might also influence particular findings, for example comments on workload and staffing may be more reflective of conditions in that area. The sample size and question format limited the analysis able to be undertaken. 


\section{DISCUSSION}

RNs working in regional Australia play a particularly important role in promoting healthy lifestyles to their patients and the community at large. ${ }^{22}$ While this study has demonstrated some adherence to recommended guidelines, it has highlighted RNs in regional Queensland may not be adhering as closely to national guidelines around healthy behaviours and that this may be impacting on their willingness to provide advice around healthy lifestyles.

Self-rated health of the cohort in this study was lower than the Australian general population as reported by the ABS. ${ }^{21}$ This could be reflective of the influence of the risk factors under investigation - whilst smoking rates were lower, and fruit and vegetable consumption were higher than the general population, alcohol consumption was higher, physical activity was lower than the general population and there were higher rates of overweight and obesity. ${ }^{21}$ These findings are consistent with another study by Perry and colleagues, ${ }^{23}$ of nurses in New South Wales, although smoking rates were twice as high in their cohort, fruit and vegetable intake, low physical activity and risky drinking were common. When considering self-rated weight however, the opposite effect of under reporting occurred. This is unsurprising given previous findings around the under estimation of self-reported weight in general. 33

The prevalence of risk behaviours is of concern both in terms of the RN's health outcomes but also the influence on providing health education. From a chronic disease perspective, as the numbers of risk factors increase, so does the likelihood of developing health problems. ${ }^{22,34,35}$ In addition to the prevalence of chronic disease rates, with the ageing of the RN workforce in Australia (current average age of 44.3 years ), ${ }^{22}$ reductions in overall health also put them at higher risk of injury and emotional disease through compromised work performance. ${ }^{5,18}$

Even though we know that adherence to healthy lifestyles directly reduces the incidence of chronic diseases and workrelated injuries as well as increasing wellbeing, there are barriers to this adherence. The high frequency of shift work was cited as a barrier in this study and this is consistent with findings from other studies. ${ }^{17,22}$ The present study identified that RNs working part-time were more likely to meet dietary guidelines, suggesting the influence of the time pressures around full-time work may have a negative influence.

However, a study by West and colleagues, ${ }^{36}$ which critically analysed findings from two previous studies, claim the opposite and assert that nurses who do shift work have more time to engage in activities such as going to the gym or exercise classes and that nurses are aware of the need to maintain health. The author's claimed that nurses can develop a shift work tolerance and use it to negotiate a more manageable work/life balance. It is important to highlight that these findings were from mid-life nurses, which is consistent with some findings within the present study. In the present study RN's in the older age brackets were also more likely to meet guidelines. Whether this is because they were less likely to have younger children creating additional demands on their time or because they have developed shift work tolerance is an issue for future investigation.

The strategies suggested by participants for assisting them to achieve health behaviour guidelines were very broad. Two of the suggestions were directed at themselves, highlighting a perceived need to prioritise, plan and make time for healthier meals and physical activity, and the desire for a better work life balance. The findings of the current study illustrated that nurses who had achieved success in certain areas such as losing weight, increasing physical activity and/ or stopping smoking felt more motivated to adhere to the recommended guidelines and confident as role models for good health. They were also more likely to feel confident in educating patients on the behaviours they had success in achieving. Whereas those who smoked or were overweight were less confident in providing education and more likely to feel hypocritical and avoid these topics with patients. Other researchers have found similar results reporting that nurses felt patients would heed advice given by healthy role models and that this would add credibility and validity to the health education they gave whilst also reflecting well on the organisation where they work. ${ }^{13,37}$ Confidence and selfefficacy in overcoming barriers and providing regular health education would then in turn improve patient care. ${ }^{13}$

Some participants in the current study believed that their own health did not impact on the care and education they provided to patients and that the fact they were not seen as 'perfect' would allow patients to feel less threatened and that they understood the same challenges. These beliefs were also reported in other studies, with some believing that if nurses' own health behaviours were seen as those of a real person, patients would connect more and that unhealthy nurses were able to provide better care as they have a greater capacity to empathise with patients as they suffer the same conditions. ${ }^{8}$ With the rising incidence of non-communicable diseases, many researchers are arguing that nurses are crucial as healthy role models and are uniquely placed to support the delivery of government and international health policy. ${ }^{23,39}$ For RNs to make a real difference to health outcomes, nurses own health and health education needs to be made a priority that is supported and implemented at multiple points: by policymakers, within nursing practice, within nursing curriculum, and in healthcare institutions. ${ }^{23,37,40}$

As mentioned earlier, this paper reports the results of the first stage of the research. These informed the development of interview questions used in phase two which delves more deeply into the value placed on health education, personal beliefs, and perceived patient perceptions around nurse credibility and patient readiness to accept education. 


\section{CONCLUSION}

The International Council of Nurses ${ }^{41}$ issued a call to action for nurses everywhere to lead the fight against chronic disease; to act as healthy role models for their families, their patients and their communities. Nurses need to be physically and mentally healthy to reliably focus on providing the best care for themselves and others. The results of this study highlight the dissonance between the health behaviours of RN's for this regional area and the national guidelines as well as the perceived influence of shift work, long working hours and family commitments on them. Whilst this was a small exploratory study, it identifies some individual and systematic challenges to RN's meeting health behaviour guidelines.

\section{IMPLICATIONS FOR FURTHER RESEARCH, POLICY, AND PRACTICE}

Facilities need to implement more strategies to enable nurses' better work/life balance especially around rostering. Nurses need to be supported to provide health education to their patients with better resources, education and time allocation. Future research should include studies conducted in different regions or ideally a large nationally representative sample.

Funding support: No funding was received in relation to the work reported in this manuscript. This research was part of a Research Higher Degree through CQUniversity Australia.

Declaration of conflicting interests: The authors declare no conflict of interest.

\section{REFERENCES}

1. World Health Organization. A comprehensive global monitoring framework including indicators and a set of voluntary global targets for the prevention and control of noncommunicable diseases [Internet]. Who.int. 2012 [accessed 10 Feb 2019]. Available from: http://www.who.int/nmh/events/2012/ discussion paper2 20120322.pdf

2. Estabrook, B, Zapka, J, Lemon, S.C. Evaluating the Implementation of a Hospital Work-Site Obesity Prevention Intervention Applying the RE-AIM Framework. Health promot pract. 2012;13(2): 190-197.

3. Bakhshi S, Fei S, Murrells T, While A. Nurses' health behaviours and physical activity-related health-promotion practices. $\mathrm{Br} \mathrm{J}$ Community Nurs. 2015; 20(6):289-96.

4. Blake H, Malik S, Mo PK, Pisano C. 'Do as say, but not as I do' are next generation nurses role models for health? Perspect Public Health. 2011;131(5):231-9.

5. Gallagher R, Perry L, Duffield C, Sibbritt D, Ying Ko C. The health of working nurses: Hypertension prevalence, awareness, treatment and control by medication. J Nurs manag. 2018 May;26(4):403-10.

6. Neall RA, Atherton IM, Kyle RG. Nurses' health-related behaviours: protocol for a quantitative systematic review of prevalence of tobacco smoking, physical activity, alcohol consumption and dietary habits. J Adv Nurs. 2016: Jan;72(1):197-204.
7. Fie S, Norman IJ, While AE. The relationship between physicians' and nurses' personal physical activity habits and their health-promotion practice: A systematic review. Health Ed J. 2013;72(1):102-19.

8. Nursing Midwifery Board of Australia. Registered nurse standards for practice. 2016. [online] Available at: http://www nursingmidwiferyboard.gov.au/Codes-Guidelines-Statements/ Professional-standards.aspx [Accessed 19 Feb 2020].

9. Beaudet N, Richard L, Gendron S, Boisvert N. Advancing population-based health-promotion and prevention practice in community-health nursing: Key conditions for change. Adv Nurs sc. 2011: Oct 1;34(4): E1-2.

10. Al Hosani S, Al Ali M, Al-Marashda K, Al-Shamsi N, Al-Ansari T, Al-Behandy A, et al. Smoking Prevalence, Attitudes and Behaviors of Primary Healthcare Providers and its Impact on Their Smoking Cessation Counseling Practices. Ibnosina. J Med \& Biomed Sc. 2015:47-55.

11. Aydin LY, Baltaci D, Ozturk S, Saritas A, Eroz R, Celepkolu T, et al. Smoking habits of nurses and midwives and their attitudes tobacco control; a primary care based study from four major cities of Turkey. HealthMed. 2012;6(12):3920-8

12. Perry L, Gallagher R, Duffield C. The health and health behaviours of Australian metropolitan nurses: an exploratory study. BMC nurs. 2015 Dec 1;14(1):45.

13. Blake $\mathrm{H}$, Harrison $\mathrm{C}$. Health behaviours and attitudes towards being role models. Br J Nurs. 2013;22(2):86-94.

14. Malik S, Blake H, Batt M. How healthy are our nurses? New and registered nurses compared. Br J Nurs. 2011;20(8):489-96.

15. Esposito EM, Fitzpatrick JJ. Registered nurses' beliefs of the benefits of exercise, their exercise behaviour and their patient teaching regarding exercise. Int J Nurs Pract. 2011;17(4):351-6.

16. Kyle RG, Neall RA, Atherton IM. Prevalence of overweight and obesity among nurses in Scotland: A cross-sectional study using the Scottish Health Survey. Int J Nurs Stud. 2016;53:126-33.

17. Jensen HI, Larsen JW, Thomsen TD. The impact of shift work on intensive care nurses' lives outside work: A cross-sectional study. J Clin Nurs. 2018 Feb;27(3-4): e703-9.

18. Tuckett $A$, Henwood T. The impact of five lifestyle factors on nurses' and midwives' health: the Australian and New Zealand nurses' and midwives' e-cohort study. Int J Health Promot Educ. 2015 May 4;53(3):156-68.

19. National Health and Medical Research Council. Australian guidelines to reduce health risks from drinking alcohol. Canberra: Commonwealth of Australia; 2009 [accessed 29 May 2016]. Available from: www.nhmrc.gov.au/ files nhmrc/ publications/attachments/ds10-alcohol.pdf

20. National Health and Medical Research Council. Australian Dietary Guidelines. Canberra: Commonwealth of Australia; 2013 [accessed 23 June 2018]. Available from: http://www.nhmrc. gov.au

21. Australian Bureau of Statistics. Australian Health Survey: Users' Guide, 2011-13 (cat. No.4363.0.55.001) [Internet]. Canberra: ABS; 2013 [accessed 15 February 2017]. Available from: https:// www.abs.gov.au/ausstats

22. Australian Institute of Health and Welfare. Australia's health 2016. Australia's health series no. 16. (cat. no. AUS 199). [Internet]. Canberra: AlHW; 2016. Available from: https://www. aihw.gov.au/reports/australias-health/australias-health-2016

23. Lin P, Xu X, Gallagher R, Nicholls R, Sibbritt D, Duffield C. Lifestyle Health Behaviors of Nurses and Midwives: The 'Fit for the Future' Study. Int J Environ Res Public Health. 2018;15(5):945 
24. Department of Health. Australia's Physical Activity and Sedentary Behaviour Guidelines. [Internet]. Canberra: Commonwealth of Australia; 2014 [accessed 12 January 2015]. Available from: http://www.health.gov.au/internet/main/ publishing.nsf/content/health-pubhlth-strateg-phys-actguidelines\#apaadult

25. Gunasekara Fl, Carter K, Blakely T. Comparing self-rated health and self-assessed change in health in a longitudinal survey: Which is more valid? Soc Sci Med. 2012;74(7):1117-24. doi: 10.1016/j.socscimed.2011.11.038

26. Dennick R, Tavakol M. Making sense of Cronbach's alpha. Int J Med Educ. 2011;2(1):53-5.

27. IBM Corp N. IBM SPSS statistics for windows. Version 22.0. 2013 Jul 29

28. Vaismoradi M, Turunen $H$, Bondas T. Content analysis and thematic analysis: Implications for conducting a qualitative descriptive study. Nurs Health Sci. 2013;15(3):398-405. doi:10.1111/nhs.12048

29. Bazeley P. Qualitative data analysis: Practical strategies: Sage 2013.

30. AlHW. Who are nurses and midwives? [Online]. Available from: https://www.aihw.gov.au/reports/workforce/nursing-andmidwifery-workforce-2015/contents/who-are-nurses-andmidwives [Accessed 23 March 2017].

31. Chakravarty EF, Hubert HB, Krishnan E, Bruce BB, Lingala VB, Fries JF. Lifestyle Risk Factors Predict Disability and Death in Healthy Aging Adults. Am J Med. 2012;125(2):190-7.

32. Commonwealth of Australia. National Strategic Framework for Rural and Remote Health. [Online]. Brisbane: Department of Health; 2016. Available from: https://www1.health.gov.au/ internet/main/publishing.nsf/Content/national-strategicframework-rural-remote-health

33. Ambwani S, Chmielewski JF. Weighing the evidence: Social desirability, eating disorder symptomatology, and accuracy of self-reported body weight among men and women. Sex roles. 2013;68(7-8):474-83. doi:10.1007/s11199-012-0244-1

34. Department of Health. Self-reported health status 2011-12. Health indicators: chronic disease and behavioural risk factors, Wide Bay Hospital and Health Service and Medicare Local detailed results. Brisbane: Queensland Government; 2013.

35. Khan SB, Hafizullah M, Gul AM, Ali J, Qureshi MS, Shah ST, et al. Frequency of coronary heart disease risk factors among nurses. JPMI. 2012;26(4).

36. West S, Mapedzahama V, Ahern M, Rudge T. Rethinking shiftwork: mid-life nurses making it work! Nurs Inq. 2012;19(2):177-87. doi:10.1111/j.1440-1800.2011.00552.x

37. Blake $H$, Patterson J. Paediatric nurses' attitudes towards the promotion of healthy eating. Br J Nurs. 2015;24(2):108-12.

38. Aranda K, McGreevy D. Embodied empathy-in-action: overweight nurses' experiences of their interactions with overweight patients. Nurs Inq. 2014;21(1):30-8.

39. Darch J, Baillie L, Gillison F. Nurses as role models in health promotion: a concept analysis. Br J Nurs. 2017;26(17):982-8

40. Garry B, Boran S. Promotion of oral health by community nurses. Br J Community Nurs. 2017 Oct 2;22(10):496-502.

41. International Council of Nurses (ICN). Delivering quality, serving communities: nurses leading chronic care. 2010. Available at: http://www.icn.ch/images/stories/documents/publications/ ind/indkit2010.pdf 